\title{
ANALFABETISMO EM PORTUGAL - OS DADOS ESTATÍSTICOS, AS POLÍTICAS PÚBLICAS E OS ANALFABETOS
}

\author{
Carmen Cavaco $(U L)^{*}$
}

\section{RESUMO}

O texto foca-se no analfabetismo, em Portugal, a partir da análise de dados estatísticos, das políticas públicas de educação de adultos e da perspectiva de adultos analfabetos. A análise, simultânea, destas três dimensões permitenos compreender que o analfabetismo é um fenómeno complexo, resultante de factores sociais, culturais e políticos, que tende a perdurar no tempo. $\mathrm{O}$ analfabetismo em Portugal, embora seja particularmente notório no grupo etário com idade superior a 65 anos, está presente em todos os grupos etários. A taxa de analfabetismo é maior nos territórios rurais e isolados geograficamente. As políticas públicas de educação de adultos têm contribuído para silenciar e invisibilizar o analfabetismo, pelo facto de não assumirem uma oferta de alfabetização de adultos, nas últimas décadas, adequada à dimensão e à complexidade do problema. Numa sociedade cada vez mais escolarizada, a persistência do analfabetismo revela um mundo injusto, onde as desigualdades são, com frequência, naturalizadas e silenciadas. O contacto com os analfabetos permite-nos perceber que a sua condição, resultante do contexto socioeconómico, é considerada pelos mesmos uma grande limitação na sua vida, geradora de um sentimento de tristeza que os acompanhou ao longo da vida, desde a infância até à velhice. Nesse sentido, a aprendizagem da leitura e da escrita revelou-se sempre um sonho por cumprir. Estes elementos reforçam a importância de se assegurar o direito à aprendizagem da leitura e da escrita a todos os cidadãos, independentemente da sua idade, através de uma política pública de alfabetização de adultos.

Palavras chave: Analfabetismo. Analfabetos. Políticas públicas de alfabetização de adultos.

* Carmen Cavaco é doutorada em Ciências da Educação, na especialidade de Formação de Adultos, pela na Faculdade de Psicologia e de Ciências da Educação da Universidade de Lisboa. É docente e investigadora no Instituto de Educação da Universidade de Lisboa. Desenvolve investigação sobre formação experiencial, adultos não escolarizados e adultos pouco escolarizados, políticas públicas de educação e formação de adultos, reconhecimento e validação de adquiridos experienciais e o método biográfico. E-mail: carmen@ie.ulisboa.pt 


\section{ABSTRACT}

\section{ILLITERACY IN PORTUGAL: STATISTICAL DATA, PUBLIC POLICY AND THE ILLITERATE}

In this text we analyse illiteracy in Portugal, based on statistical data, public policies on adult education and the perspective of illiterate adults. This analysis confirms that illiteracy is a complex phenomenon, resulting from social, cultural and political factors, which tends to persist over time. In Portugal, illiteracy, although particularly notable in the age group over 65, is present in all age groups. Its rate is higher in rural territories and places geographically isolated. In recent decades, adult education public policies have contributed to silencing and making illiteracy invisible, because they have not taken on an adult literacy offer adequate to the scale and complexity of the problem. In an increasingly schooled society, the persistence of illiteracy reveals an unfair world, where inequalities are often naturalized and silenced. The contact with the illiterate allows us to realize that their condition, resulting from the socio-economic context, is considered by them a big limitation in their lives, generating a feeling of sadness that accompanies them throughout life, from childhood to old age. Because of that reason learning to read and write has always been a dream to fulfil. These elements reinforce the importance of ensuring the right to learn how to read and write to all citizens, regardless their age, through a public literacy policy for adults.

Keywords: Illiteracy. Illiterate person. Public literacy policies for adults.

\section{RESUMEN}

\section{ANALFABETISMO EN PORTUGAL - LOS DATOS ESTADÍSTICOS, LAS POLÍTICAS PÚBLICAS Y LOS ANALFABETOS}

En este artículo se hace un análisis del analfabetismo en Portugal, a partir de datos estadísticos, de las políticas públicas de educación de adultos y de la perspectiva de los adultos analfabetos. Este análisis permite corroborar que el analfabetismo es un fenómeno complejo, resultante de factores sociales, culturales y políticos, que tiende a perdurar en el tiempo. El analfabetismo en Portugal está presente en todos los grupos de edad, aunque es particularmente evidente en el grupo de edad mayor de la edad de 65 años. El analfabetismo es mayor en los territorios rurales y aislados geográficamente. En las últimas décadas, las políticas públicas de educación de adultos han contribuido a silenciar y a tornar invisible el analfabetismo, por el hecho de no invertir en cursos de alfabetización de adultos, adecuados a la dimensión y a la complejidad del problema. En una sociedad cada vez más escolarizada, la persistencia del analfabetismo revela un mundo injusto, donde las desigualdades han sido naturalizadas y silenciadas. El contacto con los analfabetos nos permite percibir que su condición, resultante del contexto socioeconómico, es considerada por los mismos una gran limitación en su vida, generadora de un sentimiento de tristeza que los acompañó a lo largo de la vida, desde 
la infancia hasta la vejez. En ese sentido, el aprendizaje de la lectura y de la escritura se ha revelado siempre un sueño por cumplir, en su vida. Estos elementos refuerzan la importancia de garantizar el derecho al aprendizaje de la lectura y la escritura a todos los ciudadanos, independientemente de su edad, a través de una política pública de alfabetización de adultos.

Palabras clave: Analfabetismo. Analfabetos. Políticas públicas de alfabetización de adultos.

\section{Introdução}

$\mathrm{O}$ texto incide numa análise sobre $\mathrm{o}$ analfabetismo, em Portugal, a partir de três dimensões - os dados estatísticos, as políticas públicas de educação de adultos e os adultos analfabetos. Estas dimensões são abordadas a partir de três questões: Como se caracteriza o analfabetismo em Portugal, na actualidade? O problema do analfabetismo é tido em conta por parte das políticas públicas, em Portugal? O que nos ensinam os analfabetos sobre o analfabetismo e a alfabetização de adultos? A análise, simultânea, destas três dimensões permite-nos compreender, por um lado, a importância dos dados estatísticos para um diagnóstico geral sobre o analfabetismo, a nível nacional. Por outro lado, permite-nos problematizar o modo como o problema do analfabetismo tem sido silenciado no âmbito das políticas públicas de educação de adultos. Por último, o testemunho de analfabetos permite-nos analisar alguns dos motivos que justificam o analfabetismo, a relação dos analfabetos com o saber, o modo como o analfabetismo influenciou a sua vida e a perspectiva que defendem para a alfabetização de adultos.

O analfabetismo é um fenómeno social complexo, resultante de uma multiplicidade de factores - culturais, económicos e políticos (CANÁRIO, 1999; FREIRE, 1992; LAHIRE, 1999). Partindo do pressuposto anterior, assumimos que $o$ analfabetismo não depende de opções do indivíduo e da sua família, mas de elementos estruturais, o que permite um distanciamento crítico relativamente à perspectiva da responsabilização individual, que com frequência marca a discussão em torno desta problemática. Como se verifica em Portugal, o analfabetismo é um fenómeno social que "não obedece a padrões de uniformidade e aleatoriedade" (CANÁRIO, 1999, p.54), ao manifestar-se de uma forma expressiva nas regiões mais pobres, rurais e menos acessíveis, assim como em determinados grupos - as mulheres e os idosos.

Neste artigo temos apenas em consideração a questão do analfabetismo literal, que se caracteriza pela ausência de competências de leitura e de escrita. Este tipo de analfabetismo afecta as pessoas que, por razões diversas, não frequentaram a escola e não aprenderam a ler e a escrever, mas também as pessoas que não frequentaram a escola o tempo suficiente para garantir a aprendizagem da leitura e da escrita, e as pessoas que realizaram essas aprendizagens de uma forma muito rudimentar e que ao longo da vida, pela ausência de uso das competências de leitura e escrita, foram regredindo e deixaram de saber ler e escrever. Estes elementos colocam em destaque a multiplicidade de situações que podem estar subjacentes ao analfabetismo, por isso parece-nos essencial ter em conta que os analfabetos não são um grupo homogéneo, do ponto de vista dos saberes, da idade e da situação face ao trabalho. 
Os adultos analfabetos, pelo facto de não saberem ler nem escrever, confrontam-se com situações geradoras de desigualdade no acesso à informação e nas possibilidades de expressão, o que tem repercussões no seu quotidiano, nomeadamente no exercício da cidadania, sobretudo, nas situações que exigem o domínio das referidas competências. Porém, é necessário reconhecer que "nem as pessoas pouco ou nada escolarizadas são culturalmente vazias, nem as escolarizadas são meros produtos da cultura letrada" (BENAVENTE; ROSA; FIRMINO DA COSTA \& ÁVILA, 1996, p.115). À semelhança do que defende Bernard Lahire (1999), nesta análise afastamo-nos da perspectiva miserabilista, que tende a considerar os analfabetos em situação de défice, mas também não reconhecemos a perspectiva populista, que nega a importância das competências de leitura, de escrita e de cálculo na sociedade contemporânea. Nesse sentido, parece-nos essencial o investimento numa política pública de educação de adultos que integre medidas de alfabetização de adultos, orientadas numa perspectiva de "educação problematizadora" (FREIRE, 1972), que permita a valorização das experiências de vida e dos saberes dos analfabetos. Corroboramos o pensamento de José Gil (2017) quando afirma "habituámo-nos a pensar, a pensar e a gostar de pensar, e a julgar até que basta pensar para que tudo se resolva. Não chega pensar”. No caso do analfabetismo consideramos necessária uma intervenção educativa, com o apoio financeiro do Estado, para que se possa assegurar o direito à aprendizagem da leitura e da escrita a todos os cidadãos.

Ancorada nos pressupostos anteriormente identificados, a análise é estruturada em três pontos. O primeiro ponto é orientado para a análise do analfabetismo em Portugal a partir de dados estatísticos. O segundo ponto incide numa análise das políticas públicas de educação de adultos para problematizar a alfabetização de adultos. $\mathrm{O}$ terceiro ponto centra-se na perspectiva de analfabetos sobre os motivos que justificam o analfabetismo, a sua relação com o saber e a sua proposta para a alfabetização de adultos.

\section{Analfabetismo em Portugal - a leitura dos dados estatísticos}

Os dados estatísticos mais recentes sobre o analfabetismo, em Portugal, são referentes aos Censos de 2011 (Instituto Nacional de Estatística, 2012). Os dados estatísticos permitem uma caracterização da população portuguesa, com idade superior a 10 anos, que não sabe ler nem escrever, do ponto de vista da idade, do sexo e da distribuição geográfica. Os dados estatísticos da população portuguesa confirmam que o analfabetismo é um fenómeno selectivo, na medida em que coincide com a "geografia da pobreza e da ausência de desenvolvimento" (CANÁRIO, 1999, p.50), mas também com a geografia de territórios com acessibilidades mais difíceis, caracterizados por uma população mais envelhecida e marcada por fortes assimetrias socioeconómicas.

Quadro 1 - População residente analfabeta e taxa de analfabetismo, por região.

\begin{tabular}{|l|r|c|}
\cline { 2 - 3 } \multicolumn{1}{c|}{} & \multicolumn{1}{c|}{ Total } & Taxa de analfabetismo \\
\hline Portugal & 499.936 & 5,23 \\
\hline Norte & 167.451 & 5,01 \\
\hline Centro & 135.751 & 6,39 \\
\hline Lisboa & 81.807 & 3,23 \\
\hline Alentejo & 66.103 & 9,57 \\
\hline Algarve & 21.807 & 5,36 \\
\hline RA Açores & 10.250 & 4,68 \\
\hline RA Madeira & 16.767 & 6,99 \\
\hline
\end{tabular}

Fonte: Instituto Nacional de Estatística (2012). 
A taxa de analfabetismo permite-nos compreender a proporção de analfabetos relativamente às pessoas residentes que sabem ler e escrever, num determinado território, pois a taxa de analfabetismo é calculada em função da relação entre o número de pessoas residentes analfabetas, em cada região, e o número total de residentes. A taxa de analfabetismo em Portugal situa-se nos 5,23\%, sendo que as regiões Alentejo (9.57\%), Madeira (6,99\%), e o Centro $(6,39 \%)$ apresentam valores acima da média nacional. As regiões Alentejo e Centro apresentam também um índice de envelhecimento superior à média nacional, o que ajuda a compreender a elevada taxa de analfabetismo. Por outro lado, estas duas regiões têm uma densidade populacional inferior à média nacional. Além disso, as regiões Centro e Madeira apresentam um risco de pobreza superior à média nacional (INE, 2018). A análise da taxa de analfabetismo revela-nos que as regiões Alentejo, Centro e Madeira apresentam uma proporção muito elevada de analfabetos entre a população residente, situação que se tem vindo a manter há várias décadas.

Nas regiões Alentejo, Centro e Madeira uma análise por freguesia dá conta da existência de uma taxa de analfabetismo muito superior à média de região. Estes valores colocam em evidência um país extremamente assimétrico entre regiões, sendo as assimetrias reproduzidas no interior de uma mesma região, como se pode verificar nos valores mencionados de seguida. Na Madeira, a freguesia de Curral das Freiras apresenta uma taxa de analfabetismo 20,23\%, enquanto a freguesia de Santa Luzia, no Funchal, apresenta 2,98\%.
Na região Centro, a freguesia de Casteleiro tem uma taxa de analfabetismo $41,74 \%$, valor que é de 1,02\% na freguesia de Vera Cruz, em Aveiro. No Alentejo, a freguesia de São Barnabé apresenta uma taxa de analfabetismo de 33,53\%, valor que é de 2,85\% na Freguesia de São João Baptista, em Beja. A análise da taxa de analfabetismo por freguesia revela-nos que o problema se coloca de uma forma particularmente evidente em zonas rurais, isoladas geograficamente, com baixa densidade populacional e com acessos difíceis. Por outro lado, a taxa de analfabetismo é menor nas freguesias urbanas.

A análise da taxa de analfabetismo permite corroborar o seu carácter selectivo, e assim confirmar a complexidade que caracteriza este fenómeno social, marcado por factores de natureza histórica, cultural, económica e demográfica. Todavia, nesta análise interessa-nos compreender sobretudo a dimensão humana do fenómeno, porque consideramos que "por baixo da informação tangível, dos números e das estatísticas, correm fluxos de acontecimentos inquantificáveis e que, no entanto, condicionam decisivamente a nossa vida" (GIL, 2012, p.4). Neste sentido, é importante focar a análise nos elementos que facilmente são invisibilizados pelas médias estatísticas - as cerca de 500 mil pessoas que não sabem ler nem escrever, em Portugal, no século XXI, um país cuja escolaridade mínima obrigatória é de 12 anos, desde 2012. A análise do número total de analfabetos permite-nos perceber que as regiões onde se verifica um maior número de habitantes também há um maior número de analfabetos, como é o caso das regiões Norte e Centro. 
Gráfico 1 - Número de analfabetos, por região.

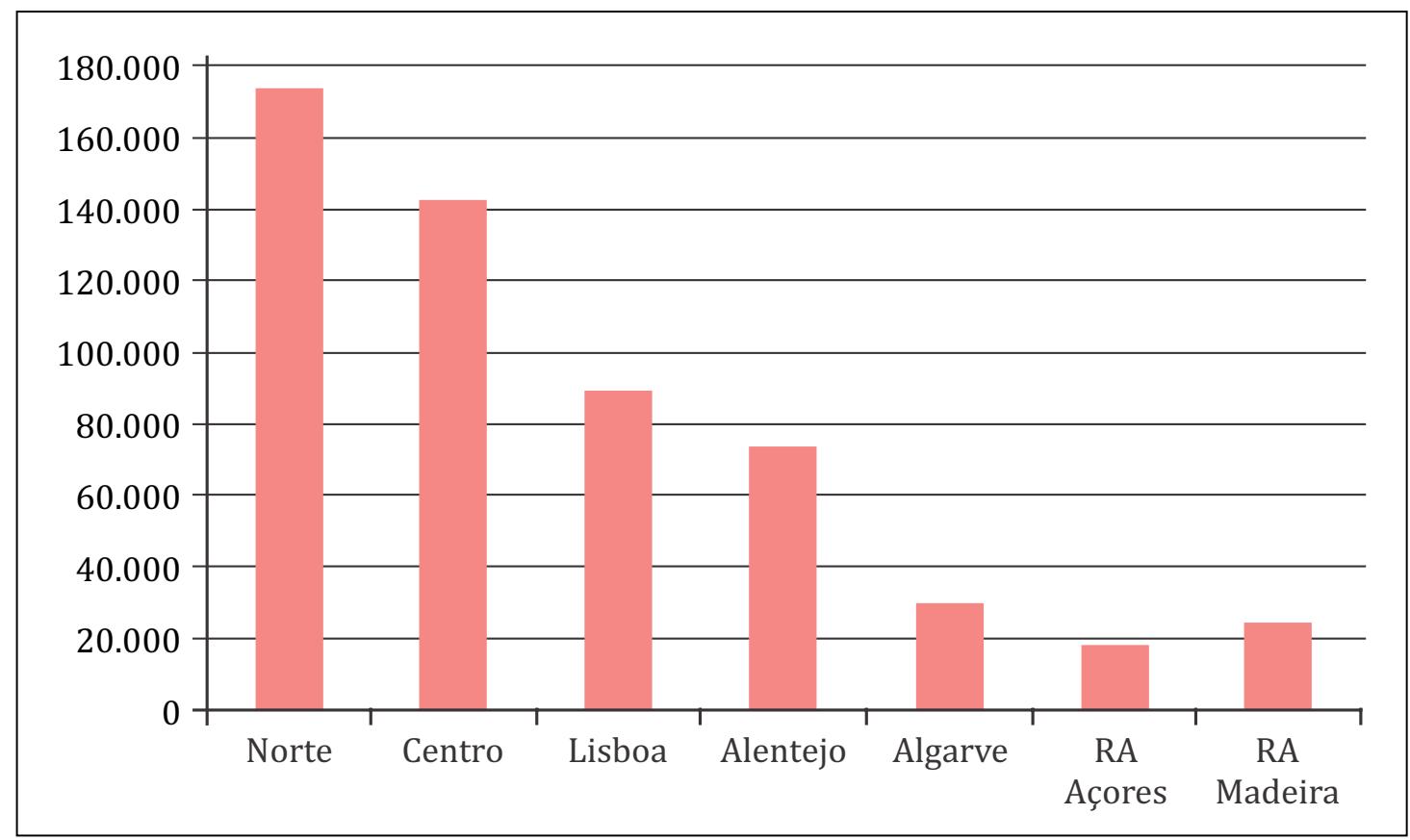

Fonte: Instituto Nacional de Estatística (2012).

$\mathrm{O}$ analfabetismo em Portugal é diferenciado do ponto de vista geracional, o que se justifica com a diferença de oportunidades de frequência e de sucesso escolar no período anterior e posterior à II Guerra Mundial. A diferença geracional que caracteriza o analfabetismo em Portugal prende-se com factores políticos, económicos, sociais e culturais complexos, que apenas uma análise histórica pode ajudar a interpretar. Em 1900, ainda durante o período da Monarquia, a taxa de analfabetismo na população Portuguesa era de $78,6 \%$, ou seja, a maioria da população não sabia ler nem escrever. Em 1920, na I República, a taxa de analfabetismo situava-se nos $71 \%$, notando-se uma evolução muito lenta na alfabetização da população, durante um período temporal de 20 anos. A evolução progressiva mas muito lenta de alfabetização da população Portuguesa é uma característica que se manteve ao longo do tempo, até à actualidade. Esta situação contrastava com a de outros países Europeus, onde a alfabetização se desenvolveu, progressivamente, entre os séculos
XVIII e XX, sendo que "entre 1901 e 1906, 97\% dos homens e $94 \%$ das mulheres sabiam assinar o seu nome" (LAHIRE, 1999, p.11). A taxa de escolarização em Portugal "em 1910 era aproximadamente a de Espanha entre 1850 e 1860" (REIS, 1993, p.17), o que deixa perceber um problema na democratização de acesso à escola, durante esse período histórico.

Durante o Estado Novo, mais precisamente entre 1926 e 1974, as taxas de analfabetismo mantiveram-se elevadas, numa estratégia de "obscurantismo programado" (MELO \& BENAVENTE, 1978). A escola nesse período histórico servia, essencialmente, como ferramenta de doutrinação das crianças e de difusão da propaganda dos ideais do governo. Contudo, a partir de 1945 com a progressiva pressão de organismos internacionais, como a UNESCO e o Banco Mundial, o governo viu-se forçado a promover, progressivamente, o acesso à escola e a investir em campanhas de alfabetização de adultos, como forma de modernização do país e de diminuição do 
analfabetismo. Porém, estas acções do Estado foram mais orientadas no sentido de melhorar a imagem do governo no exterior, do que propriamente para minimizar o problema do analfabetismo em Portugal. O progressivo investimento na escolarização das crianças permite justificar as diferenças na taxa de analfabetismo entre as pessoas que nasceram antes e após 1946. A taxa de analfabetismo aumenta de 2 a 4 décimas nos grupos etários entre os 10 e os 64 anos, o que revela uma progressiva escolarização desde 1946. Por outro lado, o valor do analfabetismo aumenta bastante no grupo etário com idade superior a 64 anos, que inclui as pessoas que nasceram antes de 1946. Estes adultos idosos analfabetos não tiveram acesso à escola e à aprendizagem da leitura e da escrita durante a sua infância, num país marcado pela pobreza, pelo trabalho infantil, e por enormes diferenças entre classes sociais.

Quadro 2 - População residente analfabeta, em Portugal, por grupo etário.

\begin{tabular}{|c|c|c|}
\hline Grupos etários & $\begin{array}{c}\text { Número de } \\
\text { analfabetos }\end{array}$ & Taxa analfabetismo \\
\hline 10 a 14 anos & 2.261 & $0,40 \%$ \\
\hline 15 a 19 anos & 2.411 & $0,40 \%$ \\
\hline 20 a 24 anos & 4.070 & $0,70 \%$ \\
\hline 25 a 29 anos & 5.460 & $0,80 \%$ \\
\hline 30 a 34 anos & 7.814 & $1 \%$ \\
\hline 35 a 39 anos & 10.423 & $1,30 \%$ \\
\hline 40 a 44 anos & 12.250 & $1,60 \%$ \\
\hline 45 a 49 anos & 13.521 & $2 \%$ \\
\hline 50 a 54 anos & 14.184 & $2,40 \%$ \\
\hline 55 a 59 anos & 16.247 & $2,80 \%$ \\
\hline 60 a 64 anos & 17.718 & $15,20 \%$ \\
\hline $65+$ anos & 392.407 & \\
\hline
\end{tabular}

Fonte: Instituto Nacional de Estatística (2012).

Nas últimas décadas, os políticos portugueses acreditaram que o problema do analfabetismo seria resolvido em algumas gerações. Primeiro, porque ocorreu um investimento no acesso à escola, por parte das crianças e jovens. Segundo, porque os adultos analfabetos tenderiam a diminuir com o passar dos anos, num processo natural, isto porque a taxa de analfabetismo era mais elevada junto dos grupos etários mais velhos. Contudo, o problema do analfabetismo ainda não se resolveu e tende a não se resolver na totalidade, porque embora tenham sido feitos esforços para assegurar o acesso a uma escolaridade obrigatória cada vez mais longa, os dados estatísticos revelam a persistência do analfabetismo entre os grupos etários mais jovens. A existência de analfabetismo entre os mais jovens revela que este fenómeno social não se resolve apenas com a definição de uma escolaridade obrigatória mais longa, sendo necessário assegurar que todas as crianças e jovens têm condições efectivas de acesso e sucesso educativo. 
Gráfico 2 - População residente analfabeta, em Portugal, por grupos etários.

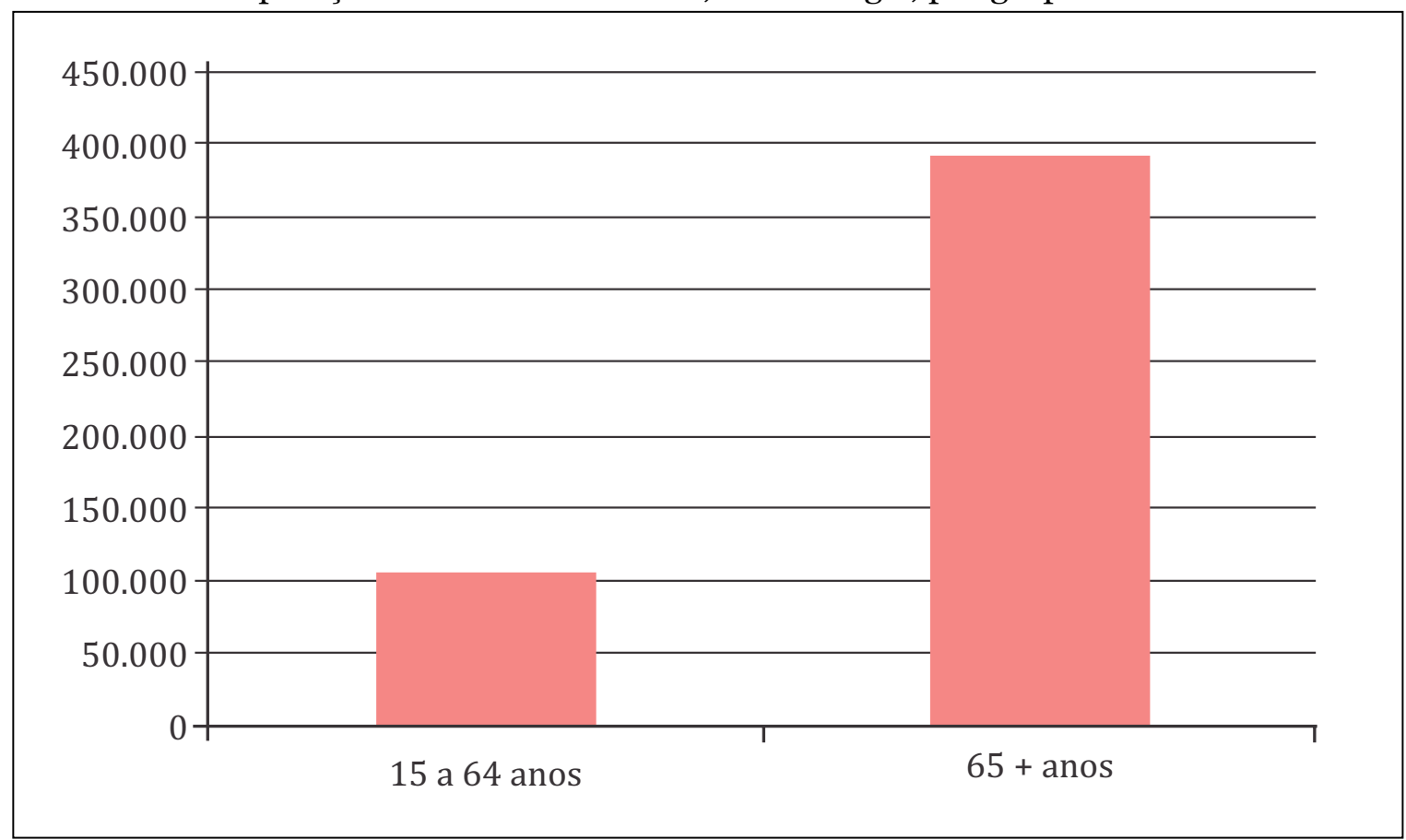

Fonte: Instituto Nacional de Estatística (2012).

O problema do analfabetismo tem vindo a ser silenciado, em Portugal, por diversas razões, entre as quais, a dificuldade de se admitir que um país integrado na União Europeia, que visa posicionar-se entre os países ditos "desenvolvidos", possa apresentar um número significativo de jovens e adultos que não sabem ler nem escrever. Por outro lado, tem-se verificado uma dificuldade em perceber a complexidade do fenómeno do analfabetismo e a sua concomitância com a escolaridade mínima obrigatória, cada vez mais longa. Outra razão que justifica o silenciamento e a invisibilidade deste fenómeno é a sua associação exclusiva aos idosos inactivos, com idade superior a 65 anos, sendo que as políticas públicas na União Europeia e em Portugal, integradas na perspectiva da Aprendizagem ao Longo da Vida, têm apenas em conta as pessoas em idade activa. Os Censos de 2011 (Instituto Nacional de Estatística, 2012) revelam que o analfabetismo está presente em todos os grupos etários, inclusivamente entre os mais jovens. Entre os 15 e os 64 anos, ou seja, no grupo etário referente à idade activa há mais de 100 mil pessoas analfabetas, em Portugal. Estes dados põem a descoberto a existência de analfabetismo em todos os grupos etários, inclusivamente, entre os mais jovens, contrariando a ideia que o analfabetismo se regista apenas junto dos mais idosos.

Em Portugal, à semelhança da tendência a nível mundial, a taxa de analfabetismo apresenta-se de uma forma diferenciada do ponto de vista do género, reflectindo uma discriminação das mulheres no acesso e no sucesso educativo. A taxa de analfabetismo é superior entre as mulheres em todas as regiões do país, com excepção da região dos Açores. Essa diferença é ainda maior nas regiões Centro, Alentejo e Madeira, ou seja, nas regiões onde o problema do analfabetismo se coloca de uma forma mais acentuada. 
Quadro 3 - População residente analfabeta, por sexo e região.

\begin{tabular}{|l|r|r|r|r|}
\cline { 2 - 5 } \multicolumn{1}{c|}{} & \multicolumn{1}{c|}{ Homens } & \multicolumn{1}{c|}{ Mulheres } & \multicolumn{1}{c|}{ \% Homens (a) } & \multicolumn{1}{c|}{ \% Mulheres (b) } \\
\hline Portugal & 159705 & 340231 & $3,50 \%$ & $6,80 \%$ \\
\hline Norte & 51434 & 116017 & $3,20 \%$ & $6,60 \%$ \\
\hline Centro & 40620 & 95131 & $4 \%$ & $8,50 \%$ \\
\hline Lisboa & 22899 & 58908 & $1,90 \%$ & $4,40 \%$ \\
\hline Alentejo & 23822 & 42281 & $7,20 \%$ & $11,90 \%$ \\
\hline Algarve & 9091 & 12716 & $4,60 \%$ & $6,10 \%$ \\
\hline Açores & 5444 & 4806 & $5,10 \%$ & $4,30 \%$ \\
\hline Madeira & 6395 & 10372 & $5,70 \%$ & $8,10 \%$ \\
\hline
\end{tabular}

Fonte: Instituto Nacional de Estatística (2012).

Nota: Em (a) e (b) a percentagem foi calculada em relação ao número total de residentes, por sexo, na respectiva região.

$\mathrm{Na}$ análise por grupo etário é possível perceber que a discriminação das mulheres apresenta um efeito geracional, ou seja, está presente a partir do grupo dos 55-59 anos e acentua-se progressivamente nos grupos etários seguintes. Nos grupos etários mais jovens, dos 10 aos 54 anos, a taxa de analfabetismo é superior entre os homens, ainda que a diferença seja pequena, com excepção do grupo etário dos 20-24 anos, em que a taxa de analfabetismo é igual entre homens e mulheres. Nos Açores a taxa de analfabetismo é superior entre os homens em todos os grupos etários, contudo nos grupos etários mais jovens a diferença na taxa de analfabetismo de homens e mulheres tende a diminuir. Estes dados mostram que as diferenças de género existentes no fenómeno do analfabetismo têm vindo a atenuar-se e até mesmo a inverter-se nas gerações mais jovens.

A análise dos dados estatísticos confirma a complexidade inerente ao fenómeno do analfabetismo, sendo este influenciado por múltiplos factores - sociais, culturais, eco- nómicos e políticos - que interferem na vida quotidiana das pessoas. Os dados estatísticos permitem-nos afirmar que o analfabetismo em Portugal não será resolvido de uma forma natural, ao contrário da crença difundida do ponto de vista social e político, o que justifica a importância do investimento em medidas de alfabetização de adultos, enquadradas em políticas públicas de educação de adultos.

\section{Alfabetização de adultos - o desinvestimento das políticas públicas}

As políticas públicas de educação de adultos, em Portugal, nas últimas décadas, não incidiram em medidas de alfabetização, o que contribuiu, em grande medida, para o silenciamento e a invisibilidade do fenómeno do analfabetismo. Os políticos têm vindo a subestimar a complexidade do problema do analfabetismo, registando-se a crença que este fenómeno social poderia ser resolvido com o acesso à escola e o aumento 
da escolaridade obrigatória, ou seja, numa acção junto das crianças e dos jovens. Em simultâneo, consideravam que o analfabetismo tenderia a diminuir e a desaparecer naturalmente, através da evolução demográfica - com a morte progressiva dos mais idosos, junto dos quais se registam as taxas de analfabetismo mais elevadas.

O desinvestimento na alfabetização de adultos, no âmbito das políticas públicas, particularmente notório, nas últimas três décadas, justifica a descida muito lenta na taxa de analfabetismo em Portugal. Essa descida deve-se, essencialmente, ao desaparecimento progressivo dos adultos analfabetos e não a medidas de alfabetização, apoiadas pelo Estado. Os dados estatísticos anteriormente analisados revelam que o analfabetismo tem maior incidência junto dos adultos com idade igual ou superior a 65 anos, todavia, está presente em todos os grupos etários. Estes valores provam que a democratização do acesso à escola e o aumento da escolaridade obrigatória, a partir de 1974, não foram suficientes para assegurar a aprendizagem da leitura e da escrita a todos os cidadãos. A existência de analfabetos nos grupos etários entre os 10 e os 40 anos, ou seja, um grupo cuja frequência escolar teria ocorrido após a Revolução de 1974 - um período marcado por uma progressiva democratização da escolarização prova que o analfabetismo é um fenómeno social complexo, o que nos suscita questões sobre o funcionamento e organização da sociedade, da escola e do mercado de trabalho. Estes dados originam algumas questões - Quem são estes jovens e adultos? Que motivos justificam o facto de não saberem ler nem escrever? Qual a sua relação com a escola e com o saber? Como percepcionam o analfabetismo e as consequências deste na sua vida?
A crença de que o analfabetismo se resolvia com o investimento na escolarização das crianças contribuiu para um desinvestimento progressivo em políticas públicas de alfabetização de adultos, nas últimas décadas, em Portugal. Por outro lado, a Agenda Global definida pelas orientações políticas de organizações internacionais, no domínio da educação de adultos, contribuiu para o silenciamento e invisibilidade progressiva do fenómeno do analfabetismo, nas últimas décadas. A UNESCO teve um papel muito importante na definição de uma Agenda Global de educação de adultos centrada na alfabetização, entre os anos 1960 e 1980. Todavia, nas últimas décadas o discurso incidiu na perspectiva da Aprendizagem ao Longo da Vida, com a instrumentalização da educação ao serviço do mercado de trabalho, o que justifica a incidência particular nas pessoas em idade activa e o investimento na formação profissional, inicial e contínua. Estes factores ajudam a compreender a demissão, por parte do Estado, para assegurar o direito à educação a cidadãos que se viram impossibilitados de aprender a ler e a escrever, na infância, a maior parte das vezes, na sequência de problemas socioeconómicos.

As políticas públicas de educação de adultos, em Portugal, nas últimas três décadas, foram expressivas mas incidiram de uma forma particular nos adultos pouco escolarizados, com domínio das competências de leitura e escrita. Ou seja, as políticas públicas foram dirigidas aos adultos mais escolarizados entre os pouco escolarizados, ignorando os adultos analfabetos, que por não dominarem a leitura e a escrita ficaram impossibilitados de usufruir da oferta pública. As ofertas dirigidas ao ensino básico, tais como os cursos de educação e formação de adultos, o ensino recorrente, o processo de reconhecimento, validação e certificação 
de competências e as formações modulares mobilizaram um total de 647124 adultos, em Portugal, entre 2007 e 2017. Durante este período temporal a única possibilidade orientada para a alfabetização de adultos, no âmbito das políticas públicas, decorreu através do programa de formação em competências básicas, com emergência em 2010. O programa de formação em competências básicas incide na leitura, escrita, cálculo e nas tecnologias da informação e comunicação, numa tentativa de colmatar lacunas nestes domínios e de assegurar o acesso às restantes ofertas de educação de adultos.

Quadro 4 - Evolução do número de inscritos no Programa de Formação em Competências Básicas, no Continente.

\begin{tabular}{|c|c|}
\hline Ano & Número de inscritos \\
\hline 2010 & 375 \\
\hline 2011 & 5710 \\
\hline 2012 & 11118 \\
\hline 2013 & 7208 \\
\hline 2014 & 6820 \\
\hline 2015 & 4838 \\
\hline 2016 & 2469 \\
\hline 2017 & 2598 \\
\hline Total & 41136 \\
\hline
\end{tabular}

Fonte: ANQEP e Conselho Nacional de Educação.

O programa de formação em competências básicas é a única oferta pública dirigida aos adultos que não dominam as competências de leitura e escrita, porém tem vindo a registar um decréscimo de inscrições, ao longo do tempo. O número de adultos mobilizados neste programa, entre 2010 e 2017, foi bastante reduzido representando apenas $8 \%$ dos analfabetos existentes em Portugal. O programa é constituído por um total de 300 horas de formação, o que nos parece insuficiente para assegurar as aprendizagens elementares de leitura e de escrita. A alfabetização exige o respeito pela temporalidade necessária por cada adulto a iniciar-se na leitura e na escrita, sem que se sinta pressionado a respeitar o ritmo definido pelo formador ou o ritmo de progressão do grupo. Por outro lado, a aprendizagem básica da leitura e da escrita são processos complexos e progressivos (Freire, 1992; Galvão \& Pierro, 2007), que carecem de treino e de aperfeiçoamento longo, como forma de se assegurar a manutenção destas competências no tempo. A alfabetização enquanto aprendizagem e aperfeiçoamento da leitura e da escrita é um processo que exige uma temporalidade longa, coincidente com a temporalidade da vida dos sujeitos, por estar sempre em evolução. Além disso, a evolução da leitura e da escrita dependem, em grande medida, do uso que os sujeitos fazem destas competências no seu quotidiano. Nesse sentido, a alfabetização de adultos não é compatível com medidas avulsas e de curta duração.

Os elementos apresentados confirmam o desinvestimento na alfabetização de adultos, no âmbito das políticas públicas de educação, em Portugal. A inexistência de medidas políticas de alfabetização de adultos inviabiliza a possibilidade dos jovens e adultos analfabetos realizarem a aprendizagem da leitura e da escrita, numa sociedade cada vez mais escolarizada e com apelo permanente a essas competências no quotidiano.

\section{Adultos analfabetos - entre 0 desejo de aprender e a crítica à forma escolar}

O contacto com as pessoas analfabetas permite-nos compreender o analfabetismo através da sua experiência de vida, o que é 
essencial para perceber que por detrás das estatísticas sobre o analfabetismo há vidas humanas, influenciadas quotidianamente pela ausência de competências de leitura e de escrita. Os analfabetos são cidadãos a quem não foi assegurado o direito de aprender a ler e a escrever durante a infância, no decurso de dificuldades socioeconómicas das famílias, de problemas de acessibilidade à rede escolar, e de problemas de organização e de funcionamento da escola. Os analfabetos apresentam, com frequência, a pobreza da família como justificação para a não frequência da escola:

"Os meus pai eram muito pobres nunca andei na escola [...] sou filha de homem pobre não me ensinaram a ler" (Maria);

"Gostava de ter ido à escola mas os meus pais não tinham condições para a gente ir [...] foi sempre uma vida de amargura" (António);

"Não vê que a gente eramos muitos [filhos], então tive logo de ir cuidar numas bestas" (José);

"Fui uns dias, tão pouco fiz lá o mês... Não tinha tempo de ir como há agora, [a escola localizava-se a 5 quilómetros de casa, percurso que realizava a pé]”" (Ilda).

A pobreza vivida no seio familiar e o trabalho infantil vivenciado pelas crianças são factores que impediram a frequência da escola, por vezes vividos com sofrimento por parte das crianças: "Eu cuidava nos meus irmãos... Depois devia ter ido à escola, não fui, chorava todos os dias que queria ir à escola [...] mas não podia" (Júlia). Estes testemunhos confirmam que a geografia do analfabetismo está associada à pobreza e ao trabalho infantil. Estes adultos iniciaram a sua vida profissional, na infância. Quando as crianças da sua idade frequentavam a escola, eles viam-se confrontados com a necessi- dade de apoiarem financeiramente a família e de ajudarem nas tarefas domésticas. A definição e imposição legal da escolaridade obrigatória é um factor muito importante, todavia, não é suficiente para assegurar a frequência da escola e o sucesso educativo das crianças, sobretudo quando as famílias vivenciam situações de pobreza e de isolamento geográfico.

O analfabetismo está associado à pobreza e às desigualdades sociais, sendo que este, por sua vez é gerador e reprodutor de injustiças sociais e geracionais. Os analfabetos "são vítimas de desigualdades" (DUBET, 2010, p.35) específicas que se conjugam de uma forma complexa e originam múltiplas desigualdades, ao longo da sua vida. Os analfabetos vêem-se impedidos de ter acesso à informação escrita ao longo da sua vida, o que lhes coloca muitas limitações no quotidiano, com repercussões em todos os domínios da sua vida, nomeadamente, na progressão profissional e na mobilidade social, elementos que mencionam:

"Perderam-se muito boas inteligências no outro tempo" (Maria);

"A gente não saber ler é sempre uma falta, sempre... faz falta para a gente chegar aí e ler uma carta, para a gente dizer melhor aquilo que diz, do que fala às vezes, faz sempre falta [...] a pessoa que sabe ler fala sempre melhor que a gente, quantas vezes... e a gente não aprendeu, pronto! Foi no tempo da miséria" (António);

"Mal empregado, Madame Júlia, você não saber ler que a gente dava-lhe um trabalho bom [...] tão trabalhadora que você é, não estava neste lugar, estava num trabalho bom [...] Estava num escritório ou numa coisa qualquer" (Júlia).

Os adultos analfabetos reconhecem a importância da leitura e da escrita, percebem os “seus usos e valores" (MELO, 1997, p.85) 
e sentem-se em desvantagem por não dominarem estas competências.

A sociedade contemporânea é caracterizada por uma grande valorização da leitura e da escrita como formas privilegiadas de comunicação, de divulgação e de acesso ao conhecimento construído historicamente pela Humanidade. A leitura e a escrita assumem um valor fundamental no quotidiano das pessoas, nomeadamente, enquanto ferramentas importantes para o exercício da cidadania. $\mathrm{O}$ aumento progressivo dos níveis de escolaridade da população Portuguesa, a valorização crescente da escola e dos diplomas são factores que justificam a estigmatização dos analfabetos. Tendo em conta a análise dos actores sociais elaborada por François Dubet (2010), podemos afirmar que os analfabetos tendem a situar-se no grupo afectado pela pobreza extrema, com tendência para se tornar invisível. Os próprios analfabetos, para evitarem o desconforto do estigma a que são sujeitos socialmente, adoptam estratégias que permitem silenciar a ausência de competências de leitura e de escrita, no seu quotidiano, como se percebe no relato "Vou por uma rua... vejo umas letras grandes, ponho-me parada [a fazer movimento de leitura com a boca]... quem não sabe diz: - Aquela mulher está lendo. Mas é mentira, estou só olhando" (Maria). O estigma social associado ao analfabetismo e o sentimento de desgosto de um sonho por cumprir - o de aprender a ler a escrever - têm vindo a contribuir para reforçar o silenciamento dos analfabetos, em Portugal.

A ausência de políticas públicas orientadas para a alfabetização de adultos, nas últimas décadas, coloca em evidência a falta de vontade do Estado para cumprir o direito à educação e à aprendizagem da leitura e da escrita aos analfabetos na idade adulta, sendo que a concretização desse direito não lhes foi, desde logo, assegurada na infância. $\mathrm{O}$ silenciamento e a invisibilidade política, social e científica podem resultar também da naturalização do fenómeno no contexto Português, devido a factores históricos e culturais. Neste caso, estaríamos perante o "efeito de acomodação a desigualdades familiares" (DUBET, 2010, p.7), caracterizadas por uma longa permanência no tempo, como é o caso do analfabetismo em Portugal, que por esse motivo passaria a ser percepcionado como uma desigualdade suportável ou menos injusta. No contacto com os adultos analfabetos percebe-se a sua tristeza e mágoa pelo facto de não saberem ler nem escrever - "O meu maior desgosto é não saber ler" (Maria); "Gostava muito de saber ler qualquer coisa, gostava muito, tenho muita pena de não saber ler" (Ana). Este sentimento de desgosto acompanhou-os em todas as fases da vida - na infância, na adolescência, na idade adulta e na velhice. Os adultos analfabetos entrevistados tinham idades compreendidas entre os 65 e os 84 anos. Ou seja, enquadram-se no grupo dos designados "inactivos", que corresponde a $21 \%$ da população portuguesa. Embora sendo um grupo muito expressivo do ponto de vista demográfico, não é contemplado nas políticas educativas de adultos, porquanto estas se dirigem apenas à população activa, ou seja, até aos 64 anos. Em Portugal, este grupo populacional é duplamente silenciado e invisibilizado, primeiro porque são idosos, reformados e já não contribuem como mãode-obra no mercado de trabalho, segundo, porque neste grupo etário há um número muito elevado de analfabetos.

Entre os adultos analfabetos entrevistados, percebe-se que a relação com o saber é muito positiva, acreditam na sua capacidade de aprendizagem e revelam uma elevada curiosidade, destacando-se um interesse 
particular na aprendizagem da leitura e da escrita:

"Se me ensinassem... uma explicaçãozinha, ainda era capaz de aprender" (Maria);

"Eu não devia ser parva se fosse à escola, porque ainda hoje me lembro de coisas que vi numa cartilha, de uma moça, que tinhas uma gansinha que dizia 'Cá, cá 'é o 'a', tinha uma garça que dizia 'pipi' é o ' $i$ ' e eu aprendi essas letras em pequenina e ainda as sei, vê lá se eu não tenho boa memória [...] foi as que me explicaram, são as que eu sei... Se aquelas me ficaram na ideia eu também fixava as outras coisas " (Júlia);

"Se as pessoas quiserem aprender, aprendem sempre... Agora já se sabe que a gente às primeiras vezes custa mais e não fica tão bem feito" (José).

Os adultos analfabetos salientam o empenho, a determinação, a atribuição de sentido, a atenção, a tentativa-erro e o aperfeiçoamento como elementos fundamentais para a aprendizagem. Além disso, a valorização da sua experiência de vida, dos seus saberes e o seu reconhecimento enquanto sujeitos com autonomia, com capacidade de pensar, de agir e de aprender são requisitos essenciais, a ter em conta, no processo de alfabetização de adultos. As falas dos adultos corroboram a importância da alfabetização ser um processo que envolve "uma compreensão crítica do ato de ler, que não se esgota na descodificação pura da palavra escrita ou da linguagem escrita, mas que se antecipa e se alonga na inteligência do mundo" (FREIRE, 1992, p.11).

Os relatos dos adultos analfabetos ajudam-nos a compreender a gravidade do problema do analfabetismo, em Portugal, no século XXI, porque este revela na sua essência uma sociedade marcada por desigualdades sociais, económicas e geracionais e uma naturalização do problema por parte do poder político, que não tem manifestado interesse, nas últimas décadas, em assegurar o direito à educação e à aprendizagem da leitura e da escrita, com uma política de educação de adultos orientada para a alfabetização. Em Portugal, é comum afirmar-se que a taxa de analfabetismo tem vindo a reduzir-se ao longo dos anos, não se manifestando indignação e análise crítica face ao número extremamente elevado de analfabetos - 499936, numa sociedade cada vez mais escolarizada. Este número identifica o número de pessoas adultas que não sabem ler nem escrever, todos têm uma história de vida, um motivo ou vários que justificam a ausência de competências de leitura e de escrita, e a vivência de muitas desvantagens e dificuldades decorrentes dessa condição, nomeadamente, no acesso à informação, à cultura, à progressão profissional e ao exercício da cidadania, situação concomitante com sentimentos de mágoa e de tristeza por não dominarem essas competências. Como podemos ficar indiferentes face a este número? Como destaca Paulo Freire (1992), é contraproducente chegarmos ao século XXI, “ostentando os índices de analfabetismo, os índices dos que e das que, mal alfabetizados, estão igualmente proibidos de ler e de escrever [...] e que com isso tudo convivamos quase como se estivéssemos anestesiados" (p.10). A naturalização e o silenciamento do analfabetismo são processos concomitantes com a naturalização e o silenciamento da pobreza e das desigualdades sociais, tornando-se mais difícil que os próprios analfabetos reivindiquem ao Estado o seu direito para aprender a ler e a escrever. Nesse sentido, parece-nos que a sociedade civil e a comunidade científica têm uma responsabilidade acrescida na exigência de financiamento, por parte do Estado, de medidas de alfabetização de adultos, adequadas do ponto de vista dos 
conteúdos e dos modos de trabalho pedagógico, às expectativas, às experiências de vida e os projectos dos analfabetos. O processo de alfabetização de adultos, do ponto de vista político, científico e social, incorpora uma importante dimensão ética, a ter em conta nas reivindicações e exigências - necessitamos de uma sociedade melhor e mais justa (SOUSA SANTOS, 2007).

\section{Referências}

Benavente, Ana (Coord.); Rosa, Alexandre; Firmino da Costa, António \& Ávila, Patrícia. A literacia em Portugal: resultados de uma pesquisa extensiva e monográfica. Lisboa: Fundação Calouste Gulbenkian e Conselho Nacional de Educação, 1996.

Canário, Rui. Educação de Adultos: Um campo e uma problemática. Lisboa: Educa, 1999.

Dubet, François. Les inegalités multipliées : La Tour d'Aigues: Éditions de l'Aube, 2010.

Freire, Paulo. A importância do ato de ler. São Paulo: Cortez Editora, 1992.

Freire, Paulo. Pedagogia do Oprimido. Porto: Afrontamento, 1972.
Galvão, Ana Maria \& Di Pierro, Maria Clara. Preconceito contra o analfabeto. São Paulo: Cortez Editora, 2007.

Gil, José. Esta tragédia é em parte o nosso espelho. Jornal de Negócios, 27 de Outubro, 2017.

Instituto Nacional de Estatística (2012). Censos 2011: Resultados Definitivos. Lisboa: INE.

Lahire, Bernard. L'invention de l' «illettrisme». Paris : La Découverte, 1999.

Melo, Alberto \& Benavente, Ana. Educação Popular em Portugal (1974-1976). Lisboa: Livros Horizonte, 1978.

Melo, Orlinda. Alfabetização e Trabalhadores: O contraponto do discurso oficial. Campinas e Goiâna: Editora da UNICAMP e Editora da UFG, 1997.

Reis, Jaime. O analfabetismo em Portugal no século XX: uma interpretação. Colóquio Educação e Sociedade, 2, p.13-40, 1993.

Sousa Santos, Boaventura. Renovar a teoria crítica e reinventar a emancipação social. São Paulo: Boitempo Editora, 2007.

Recebido em: 15/11/2018 Aprovado em: $01 / 12 / 2018$ 